\title{
A Case Study on Generative Building Skin Forming by Employing Building Information Modelling (BIM) Tools
}

\author{
Veli Mustafa Yönder ${ }^{1 \odot}$ \\ ${ }^{1}$ Res. Asst. Faculty of Architecture, İzmir Institute of Technology, İzmir, Turkey. Email: velimustafayonder@gmail.com
}

\begin{abstract} Purpose

This study aims to produce generative curtain wall geometries based on predetermined parameters such as storey information, shadow zones, preliminary building unit cost, frequency, etc. in a BIM platform for the preliminary design of a future project in Basmane and understand its novel outcomes and implications.

Design/Methodology/Approach

The methodology is construed over four successive phases, namely: the built environment modeling, analyses for a solid understanding of the study area, determination of the generative design criteria, and finally design solutions. In the initial phase, the case-study building in Basmane with the surrounding environment was digitally modeled for the following analyses. Several programs apart from BIM have been utilized for the daylight zones and wind simulations. The daylight areas affecting the surface of the studied building were marked schematically per the simulation data. Subsequently, the area of the curtain wall, material type, preliminary building unit cost (assembly/labor and material cost), the height of storey, the density of elements, and fixed shading devices parameters were tested via optimization thru generative design methodology and provide potential design solutions by utilization of BIM tools.

Findings

The findings of this study could be boiled down to a single comprehensive objective of generating outputs of assorted design solutions thru a generative design approach. When the output data set is visualized via parallel coordinate graphs, it could be well articulated that the classification of rulebased relationships and the criteria interrelations were based on the designer's decisions.

Research Limitations/Implications

This study was examined on a case basis by an experimental approach. It shall be considered that the curtain wall construction encompasses diverse materials, connection details, and construction techniques that affect the final cost thus this research was conducted at the preliminary design stage and might not reflect actual costs.

Social/Practical Implications

Albeit the technical aspect of the curtain walls is not included in this case study, it helps generative design culture by demonstrating the extent of the opportunities it offers to designers in the preliminary design stage.

Originality/Value

This study is a show-case of a preliminary design for an actual building stock in the vicinity of Basmane focusing on the building envelope design process with multiple parameters and should be regarded as an opportunity to understand how innovative solutions alike are put forward for the use of designers.
\end{abstract}




\section{INTRODUCTION}

Multi-dimensional and intricate building design processes involve numerous dissimilar meta-design methodologies and complex building development procedures. Digital building design and modeling via BIM tools facilitate the holistic handling of the design and construction processes (Eastman et al., 2011, p. 1). Besides, the real benefits of digital information modeling are best appreciated in designing complex structures, overseeing construction phases and building operations, creating as-built drawings, and assisting project management efforts. Naturally, BIM improves design documentation quality by allowing the sharing and coordination of drawings across the entire design team to minimize errors and cross-discipline clashes (Migilinskas et al., 2013). Congruently, digital mockups guide not only the novice designers but also the experts starting from the preliminary design stage to the final product as computer-generated models with detailed representation of the building components eases the understanding of the whole design at varying levels of detail. In the façade design, manufacturing and assembly phases, making use of novel digital methods such as BIM tools and their innovative strategies in place of traditional approaches is feasible. Each building façade system has gained a unique physical character by advances and innovations in technology and its implementation contained multiple peculiar parameters that affected its design cycle directly. The harmony of aesthetic concerns with the building components and environmental factors is one of the main parameters that necessitates a series of analysis and revisions which is easily realized in the BIM environment and that entails virtual simulations and real-time calculations accordingly. Moreover, these calculations and simulations can be utilized to assist in pre-design approaches as well as digital fabrication techniques, pre-fabrication methods, and on-site production options which would force the designer to develop competent virtual 3D mock-ups. Furthermore, conjoined efforts of BIM and generative design tactics can make it probable to dominate the early design process and set ultimate design approaches.

Differing from the traditional design process, the generative design employs a set of algorithms that mimics nature's evolutionary approach in the pursuit of attaining a variety of design outputs thru manipulation of the parameters and goals (McKnight, 2017). Chase (2005) asserted that generative design tools are based on key design concepts known as "procedures, geometry, encapsulation, recursion, reiteration, spatial relations, and transformations". Furthermore, 'structural analysis, form-finding, and energy modeling' can be utilized in a framework with a generative design process (Mirtschin, 2011). Apart from the aforementioned concepts, daylight can be included in this operation cycle registering a wide range of values (Gagne \& Andersen, 2012). The functions provided within Autodesk Revit 2021 software package, namely, the 'workspace layout' and the 'optimizing the window views' 
A Case Study on Generative Building Skin Forming by Employing Building Information Modelling (BIM) Tools

represent the intersection area between BIM and generative design (Autodesk Blog, 2020). These specialized tools help designers make preliminary design decisions and suggest optimized reactions to the design problems. Nowadays, the generative design approach is more BIM-based than CAD-based thus it is inevitable to adopt an unorthodox approach than what is originally available (Ferreira \& Leitão, 2015). GD forms a bridge between the creator and the final product and serves as a medium for the automation of several connected steps. The affinity of designers with sophisticated digital tools empowers them to automate or semi-automate some geometry creation steps. Such as, the digital prototypes created by parametric design can be given their final form under the control of the designer. On the contrary, in the generative approach, multiple design solutions can be offered for the user thru optimization. Briefly, generative design (GD) workflow is phased in three sections, namely, "pre-GD (data collection, determining constraints), GD (generate, evolve, evaluate), and post-GD (critical human involvement/manual design refinement)" (Villaggi \& Nagy, 2019). In this context, this study explores the implementation of generative design under the BIM environment in the case of the curtain wall geometries. For the preliminary design phase, the benefits and disadvantages of this approach are scrutinized through a study model via certain parameters.

\section{BACKGROUND OF CONTEXTUAL FRAMEWORK}

Before understanding the interaction between BIM technologies and generative design methodologies, it is essential to have a solid understanding of these two distinct concepts in an individual setting and discuss their co-development progress. For this reason, the relationships established by optimization models, genetic algorithms (GA), and artificial neural networks (ANN) are collectively put in use to comprehend the overall concept from the perspective of the generative design domain. Genetic algorithms (GA), listed among the techniques used in evolutionary design procedures, assist decision-makers by augmenting the possibilities offered by design evolution through specific software platforms (Abrishami, Goulding, Rahimian \& Ganah, 2014). Moreover, the genetic algorithm (GA) has superior features that can be used in resolving engineering design perplexities (Tayfur, 2014, p. 203) via combining design components in a revolutionary way. Genetic algorithms, one of the most popular methods of evolutionary computing with application versatility (Renner \& Ekárt, 2003), appeals also the architects and artists to develop ambidextrous solution strategies and overcome certain design challenges (Bentley, 1999) thru which the most appropriate route is selected in the presence of multiple convenient results for the target environment. Meanwhile, all phases are carried out with dependent and independent variables under the control of influential factors. The concept of generative design, which was initially adapted to architecture by a design theorist named John 
Frazer in the 1970s, has been researched from a theoretic and avantgarde perspective holistically (Frazer, 2002). Generative design culture benefits from various processes such as "self-organization, swarm systems and ant colonies, evolution, and generative grammars" (McCormack, Dorin \& Innocent, 2004). The generative design supports the design process and enhances the designer's current abilities thru the utilization of parametric concepts such as grammar, rules, and a defined set of products which renders computers more than mere modeling mediums (Shea, Aish \& Gourtovaia, 2005). CAD systems and generative design can be intermingled. As such in Krish's (2011) study, CAD-based generative design variations are final outputs of designated design problems filtered thru certain semantic system criteria such as cost, manufacturability, geometric viability, etc. Albeit the well-defined problem is multi-dimensional, the designers expect rational outputs in concert with architectural concerns from the generative design technique.

Generative design (GD) systems have been auspiciously employed in various innovative ways (Singh \& Gu, 2012). These "virtual geometric processes" require the use of parametric constraints and intense numerical controls (Garber, 2014). The design optimizations assist in describing the relationship between parameters and sub-parameters formed by measured datasets run through holistic sophisticated models. Besides, by the assistance of data harnessed from dependable quantitative sources, the ability of switching from primitive to advanced forms can be acquired with advanced algorithms. The boundaries of geometry can be iterated according to several parameters introduced by rule-based definitions. One of the prerequisites for the creation of geometric variations is to maintain the losslessness of the rule and determinants for the targeted criteria. Thus, when determining the design scheme, it is necessary to have an accurate definition of the precursors and successors of the problem while overseeing a compatible relationship between the inputs. Hence, it is possible to access and re-interpret the solutions desired by the designer using scripts inherent to the digital tool. Intensive calculations and analyzes can be performed through advanced softwares/add-ons to ensure the operability of the optimized algorithm. A special iterative automated design package called "Generative Components" by Bentley provides designers with advanced toolsets to combine geometric modeling and programming to form architectural databases (Aish, 2003). Another digital tool is the Grasshopper, which offers algorithmic modeling, an add-on for Rhinoceros 3D software (Grasshopper 3D, 2019). This advanced add-on can be used both in computational design and exploration of experimental geometries. This program can also contribute to the creation of the form for digital fabrication such as CNC and 3d-printing. Processing, a programming language, allows users to perform "generative artwork" and "visualization" (Gross, et al.,, 2012). 
A Case Study on Generative Building Skin Forming by Employing Building Information Modelling (BIM) Tools

\section{Building Information Modelling (BIM) Systems}

Advances in computer-aided design systems affect the perceptions of 2D architectural representations and 3D digital drawing environments. However, these perceptions play a key role in the diversification of the design not only thru the aesthetic concerns but also the systematic composition. In that sense, CAD is a unique tool for architects and designers to manage geometric operations with digital commands. Basic functions such as the creation of wireframe models, dimensioning of data, and the creation of surfaces that are keen to the CAD platform got transferred themselves onto BIM. The transfer of architectural geometry to a virtual environment is handled thru the principles of the CAD framework which is bound by $\mathrm{X}, \mathrm{Y}$, and $\mathrm{Z}$ input datasets (voxel). Besides, owing to the implementation of voxel definition, the designers gain the ability to transfer various geometric drawing types (2D and 3D) to the digital environment via a chain of commands at their disposal. Since the CAD environment only allows the creation of geometric objects, drawings cannot be converted into interrelated building components. One of the fundamental differences between BIM versus CAD-based platforms is the coexistence of architectural, structural, and mechanical objects. All components in the BIM environment (fonts, templates, doors, windows, curtain walls, columns, floors, mechanical elements, furnishings, etc.) carry semantic data with regards to geometric information (width, length, height), attribute tables, and non-graphical features. Moreover, the establishment of parametric links makes the interaction between the objects possible unlike 2D CAD-based drawings (Wong \& Fan, 2013). BIM is a multi-layered virtual system that helps to understand and supervise the building's overall digital transformation process in detail. Furthermore, unified efforts of making digital replicas of all structural, architectural, and MEP elements under BIM allows effective control of the design process.

Currently, BIM is appraised as a new way of approaching the design, construction, and maintenance of buildings (Bryde, Broquetas \& Volm, 2013). The client's project and building performance requirements could be met by utilizing BIM in the design phase. Meanwhile, the utilization of BIM throughout the construction process promotes communication between design, construction, and manufacturing teams with implications on schedule, rework, and cost (Sebastian, 2011). Besides, a partial and complete visualization of the building is advantageous for designers, engineers, and contractors (Eastman, et al., 2011, p. 503). Objectives of ensuring compliance with regulations and standards, working interactively in dissimilar domains, and expediting cost estimation are the main drivers for exploring BIM (Figure 1). Opportunities for facilitating coordination between the teams and solving mutual problems are the extent of BIM cooperation. Being able to work at different levels of detail (LoD) allows complicated building elements to be separated according to their detail levels, and helps reveal different layers of the project (Fai \& Rafeiro, 2014). For a better 
model visualization and user interaction, BIM provides a set of eloquent visual instruments such as showing original joints in full detail or allowing partial sections of the 3D model.

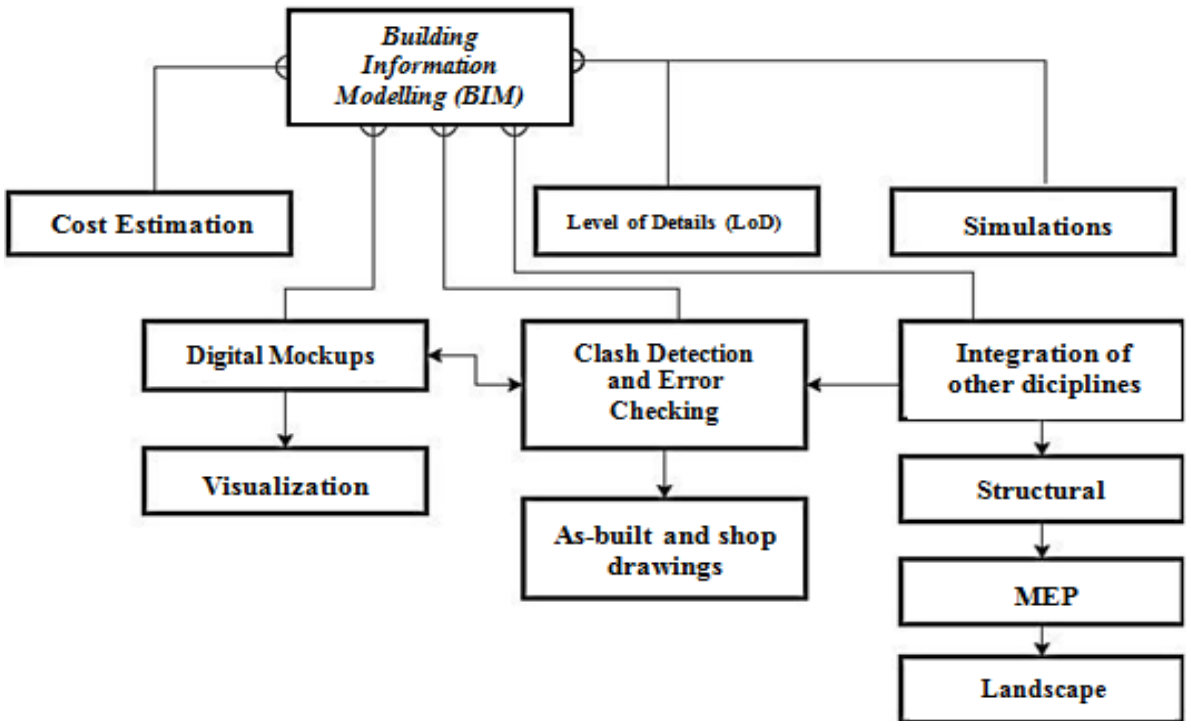

Figure 1. Operation scheme of BIM in a typical construction project.

Moreover, structural (columns, beams, slabs, etc.), mechanical (electrical, plumbing, ventilation, etc.), and architectural components (windows, doors, curtain wall, walls, ramps, stairs, etc.) can be overlapped in a BIM environment. Thus, the project's holistic perception and management gains are at disposal of decision-makers and project coordinators. Clash detection analysis, which requires the combined input of project stakeholders on a common 3D platform, can help prevent incorrect manufacturing and potential re-work, and costs and schedule impacts associated with it. Using BIM in the pre-construction stage has dissimilar purposes and obvious consequences (Latiffi et al., 2013). Besides, pre-construction design reviews can be carried out as part of error-checking procedures. Eventually, special material and detail solutions have been offered by custom add-ons to expand BIM capabilities to ameliorate how certain components of the building are created (roofs, façades, balconies, etc.). In particular, numerous add-ons provide solutions for the integration of prefabricated structural elements in the BIM model. Similarly, several specialized extensions could be exploited to create alternatives for a building skin design. Recently introduced technologies, namely, (VR) and augmented reality (AR) domains are gradually gaining a niche in building visualization and being implemented under the BIM hood. Design components can be examined in more detail via VR experience in the BIM environment (Wang et al., 2018). On the other hand, the collaboration between BIM and GIS (Geographic Information Systems) environment is capable of providing a holistic approach between construction, architecture, and engineering domains. Ability to exchange data between multiple environments, problems regarding infrastructure and superstructure can be handled with a holistic approach from a BIM, GIS, and facility 
A Case Study on Generative Building Skin Forming by Employing Building Information Modelling (BIM) Tools

management (FM) standpoint (Kang \& Hong, 2015). Besides, cooperative use of GIS and BIM technologies contribute to urban planning with rational and sustainable solutions (Yamamura, Fan \& Suzuki, 2017). Real-time simulations and calculations pertinent to building science can be accomplished with uttermost precision in the BEM (Building Energy Modelling) environment.

BIM, being an advanced digital tool, is at the disposal of sustainable architecture (Krygiel \& Nies, 2008). The interpretation of the data from the simulations (building envelope thermal energy analysis, daylight and artificial lighting simulations, etc.) and the design decisions are reviewed in the early design phase (Negendahl, 2015). These decisions are later updated per the feedbacks. The outputs of artificial lighting analysis are not only appraised in the design evaluation process of the energy models but also forms a basis for lighting element assortments and their locations (Elbiz \& Yönder, 2020). One emerging use of the BIM platform is the creation of as-built models of historical buildings (Barazzetti et al., 2015; Dore et al., 2015; Murphy, McGovern \& Pavia, 2009). A 3D model replica of a historic building can be created using the reference images obtained via photogrammetric methods. Later on, structural and mechanical components are brought into this model and overlapped to achieve a complete design package. Thus, this final BIM document serves as a cultural heritage digital archive.

\section{METHODOLOGY}

This section is structured in four phases that examine the interoperability of BIM and generative design approaches on a case basis (Figure 2). The first step was to create a virtual model to understand the effects of daylight conditions and wind forces on the building and its surroundings throughout the year. Digital applications such as SketchUp 2019 for modeling the built-environment, Autodesk Revit 2020 for creating the BIM project, Autodesk Flow Design, a computational fluid dynamics (CFD) software, for simulating virtual wind behaviors, and Shadow Analysis 2 software for calculating shading time of the built environment were employed respectively. The second step was to create an approximate material list of the curtain wall construction and attain unit prices from varying sources such as the Ministry of Environment and Urbanization, private construction companies, and architectural offices to form a cost break-down list. Later, the assembly/labor and material costs were transferred to the Autodesk Revit environment and quantity take-off sheets were created accordingly. At this point, the objective of organizing data for comparative tabulation is met. The third step was to exploit complementary digital platforms such as Project Refinery Beta and Autodesk Dynamo for the generative design phase. These packages require knowledge of node-based visual scripting for defining the relationships between parameters. An initial accurate definition of the input data requires a certain degree of competency in the management of these advanced technological tools and iron out problems in the pace 
of the process. As such, the creation and control of the geometry, the harmonious operation of the parameters, and the processing of outputs thru specialized definitions all facilitate the process.
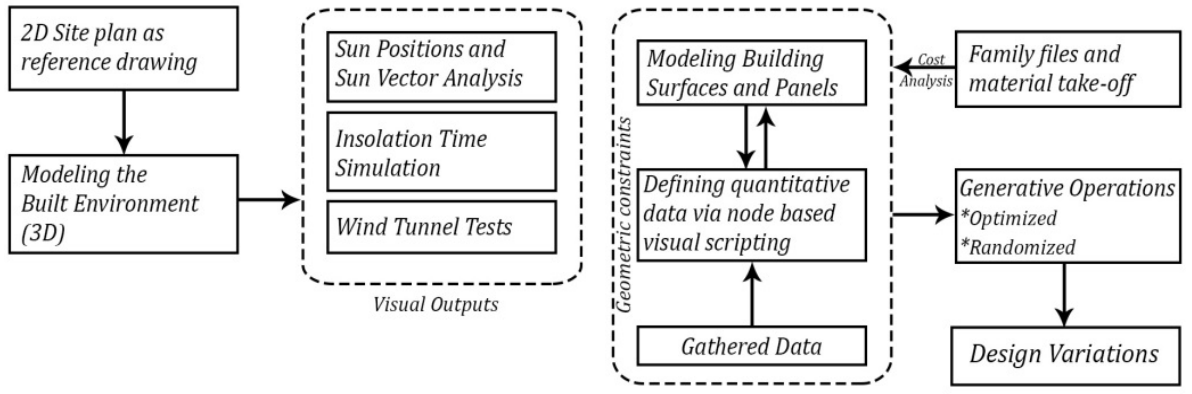

The highlighted building (Figure 3) subject to this case study is located in the Basmane district of İmir which is also appraised for its historic organic urban texture. This district reserves an invaluable place in the urban memory with its multi-layered historical structure and enriched cultural heritage bestowed throughout the centuries.

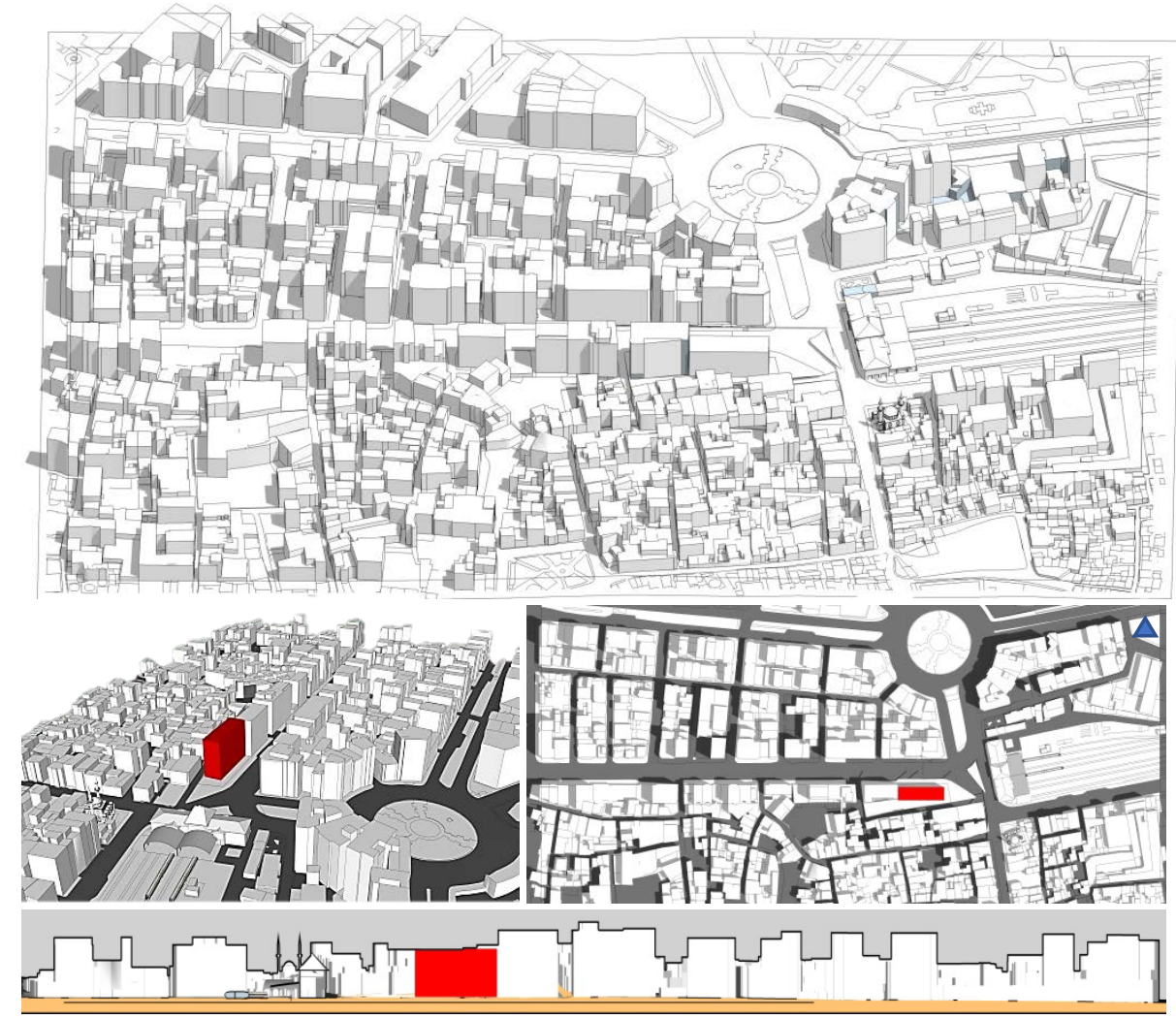

Figure 3. The project area and its vicinity: Basmane, İzmir. Methodology Workflow.
Figure 2. Presentation of the
Geographically, the İzmir climate shows Mediterranean characteristics, thus summers are usually dry and hot, and winters mild and rainy (MGM, 2019). The temperatures throughout the year are the hottest between July and August and the coldest between January and February (MGM, 2019). Based on this meteorological information, protection from the daylight is mostly needed between summer and autumn. The 
A Case Study on Generative Building Skin Forming by Employing Building Information Modelling (BIM) Tools

environmental agents driving a designer's decision can be multi-layered. In the context of this study, the output of these agents aid in determining the orientation and position of the building skin components, and the location and size of the openings. Elements of computed geographical data comprise a series of values namely: latitude, longitude, time zone, and altitude. Likewise, this formation was elicited for the case project area. Months from summer to autumn, which have relatively higher temperature records, were best suited for understanding sun vectors and positions (MGM, 2019). Archetypally, the acquired geographical data (sun azimuth and sun altitude values) for the $28^{\text {th }}$ of October (autumn season) at 03:00 pm were noted as 179. 49 and 38 50 whilst for the $28^{\text {th }}$ of July (summer season) at 11:00 am were noted as $86^{\circ} 15$ and $28^{\circ} 2$ respectively (Figure 4 ).

Figure 4. Sun vector positions in summer and autumn season at studied zone.
Figure 5. A daily shading duration analysis of the case study area during the summer season.

The analysis image sequence is marked with light yellow areas which represent the shortest shading duration and dark blue areas which represent the longest shadIng duration as shown in maps and isometric views.
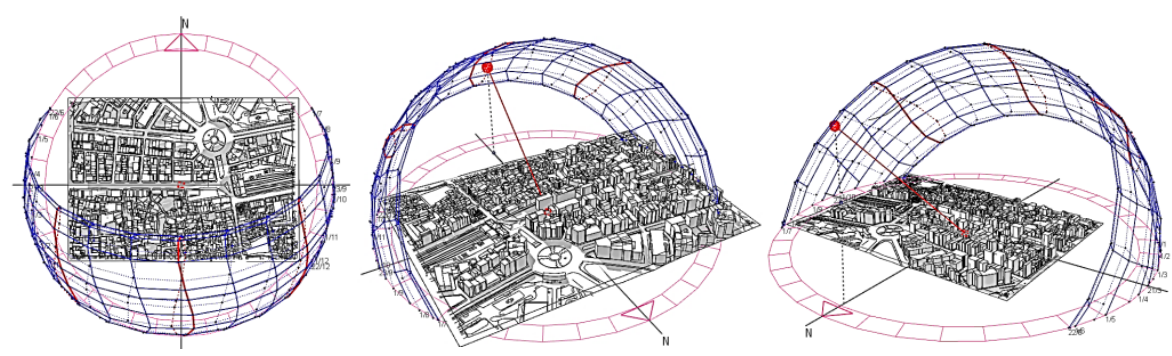

After calculating the sunlight behavior, the daylight conditions were tested on the case building model with the surrounding environment model. Analyzing the insolation conditions in this region with a highdense building development will affect the transparency-solid ratio of the devised curtain wall. After entering the data set (seasonal and hour based sun positions) into the program's equitation, the daylight conditions of the region were formulated with Shadow Analysis software (Figure 5).

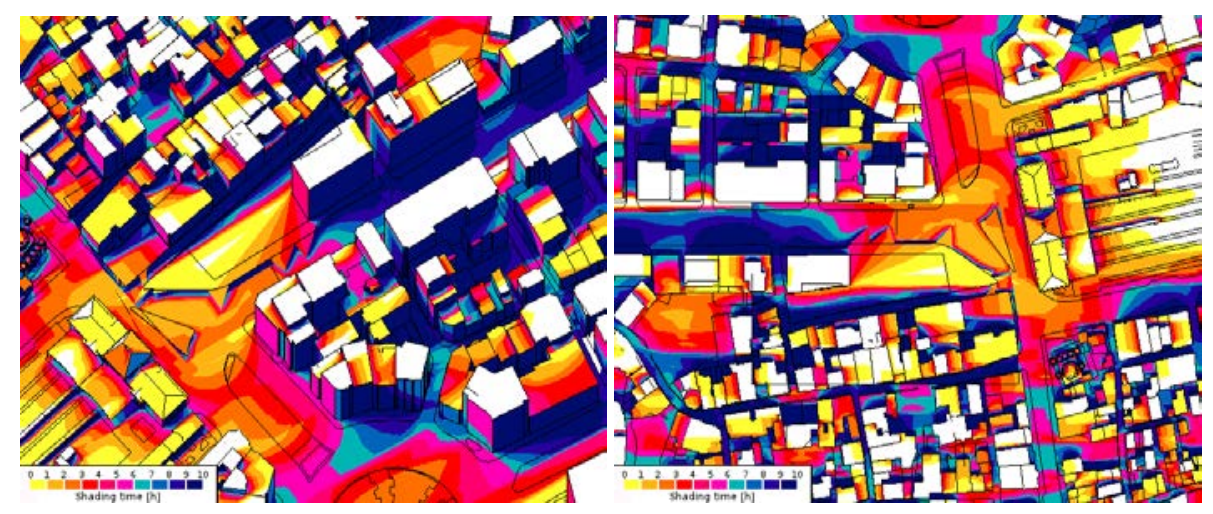

The average shading duration on the main street was found to be approximately six hours per the performance map which was highly impacted by high and dense building stock. On the contrary, the case study having been located on a corner parcel has greatly decreased the shading duration compared to other neighboring buildings along the 
street. Besides, for the single and two-storey buildings located in the south of the high buildings along the main street, shading duration was significantly high. Yet the shading duration of one and two-storey buildings on the east side was dramatically low. On 25 July 2019, a monitoring study accessing the extent of daylight and shading areas on the façade at various hours of the day was conducted to identify dispersion of the solid and porous/transparent surfaces schematically (Figure 6).

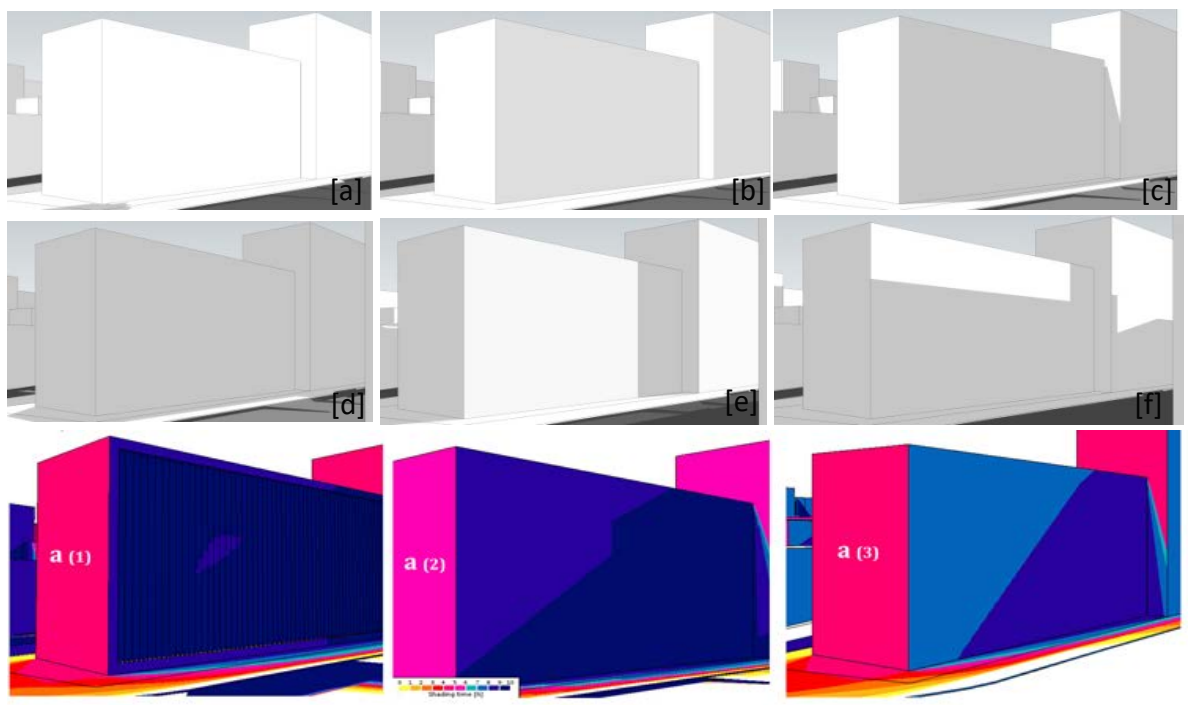

Finally, these observations transpired as schematic image-based outputs (2D) that will be used to decide on the type of building façade materials. Then, digital wind flow modeling studies on the entire 3D model were carried out to determine the wind forces and zones that the building and its surroundings were exposed to (Figure 7).

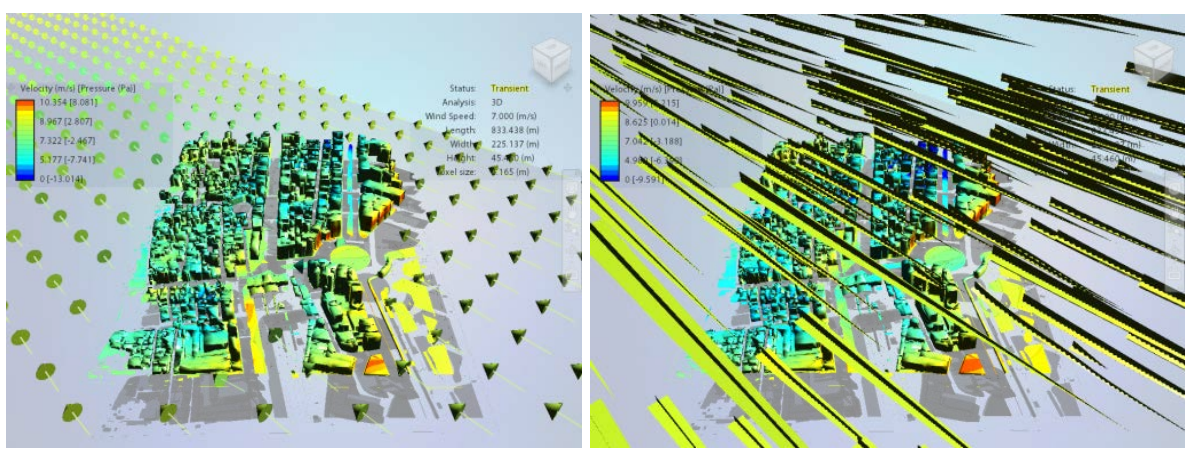

The average velocity was marked as $3 \mathrm{~km} / \mathrm{h}$ in the northeast direction during the winter season (MGM, 2019). Hitherto, color mapped analysis for the daylight conditions and wind are merely 2D sequential representations of the phenomenon to better understand physical environmental conditions. Preparation of an elaborate façade model before utilizing these reference images gives a rough idea about the project cost (assembly/labor and material) (Figure 8). It should be
Figure 6. The visual presentation of the shading duration and daylight analysis of the building façade on $25^{\text {th }}$ of July at below hours:

[a] 06:30 am 25 July 2019

[b] 07:30 am 25 July 2019

[c] 10:30 am 25 July 2019

[d] 01:30 pm 25 July 2019

[e] 05:30 pm 25 July 2019

[f] 06:30 pm 25 July 2019.

Figure 7. Wind flows and their distribution of the case district. The velocity value $(\mathrm{m} / \mathrm{s})$ is represented by a color scale ranging from blue to orange in an ascending magnitude. 
Figure 8. Curtain wall system modeled via BIM tools and corresponding material take-off lists in Excel
A Case Study on Generative Building Skin Forming by Employing Building Information Modelling (BIM) Tools

noted that input on floor heights, slab thicknesses, and proposed cladding techniques are needed before designing a variety of curtain wall systems and their virtual models. Based on these models, corresponding project material lists were prepared at a sufficient level of detail for the preliminary design phase. Furthermore, unit prices from varying sources such as the Ministry of Environment and Urbanization, private construction companies, and architectural offices were solicited to gather a cost break-down list for each design alternative. The cost estimation lists for assembly/labor and material were transferred to the Autodesk Revit environment and quantity take-off sheets were created accordingly (Figure 8). At this point, the processed data is suited for comparative tabulation.

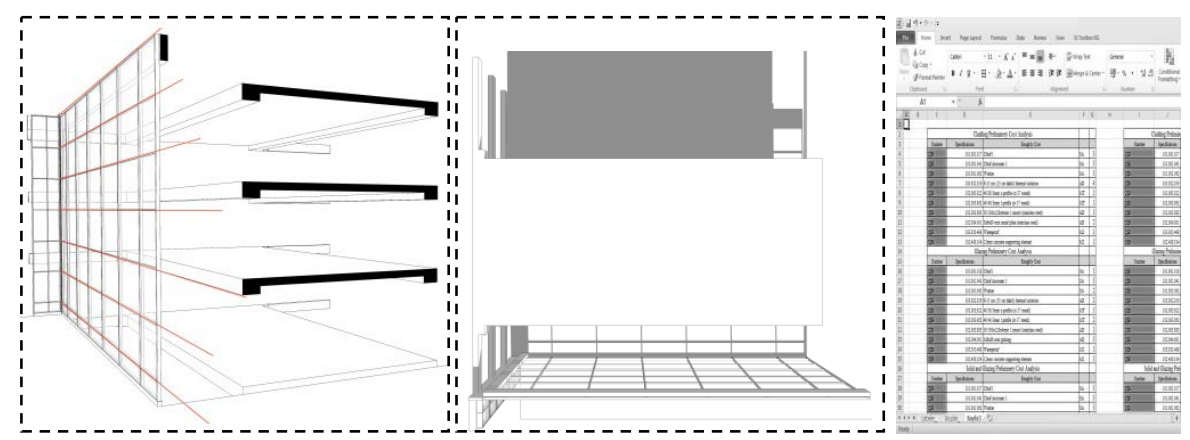

As it is indispensable for the generative process, the following phase involves algorithmic expression of the design geometry thru semiautomated definitions and inputs. The procedure of creating geometries for the generative design was accomplished thru Autodesk Revit 2020, Autodesk Dynamo environment, and Project Refinery Beta resources. By exploiting node-based visual scripting capabilities of the Dynamo, the geometry can be redefined and reiterated to meet design objectives set by common operations of independent or dependent parameters. Dynamo requires the input of a set of points before solving any form. In this respect, a series of points were created on the façade to form an evenly distributed grid line. Then, the width, length, and height values of the building volume were determined and made available before the processing of the façade geometry. The thickness and the area of the construction geometry are interrelated with the grid lines. These geometric data bridge operations are generally nested lists. This ensures minimal data loss between the control and compatibility of surface components so that area-based calculations and the intersection points of the grid lines can make a geometric connection between each other (Figure 9). The curtain wall components were placed to match the given grid lines. The rectangular solid surfaces match the user-defined base grid system(s) according to the building surface design. The number of divisions on a given grid could be manipulated by integer input sliders on the $\mathrm{X}$ and Y-axis. These manipulations have an immediate effect on the arrangement of vector lines, façade component 
thickness and density. Per se vertical lines represents vertical curtain wall components fixed on the building structure. After the placement of low detailed horizontal and vertical curtain wall structures (except the load-bearing profiles, connection details, and glass material details) on the grid, material types (composite cladding and curtain wall glass) were identified according to reference 3D model created by traditional methods in the BIM environment.
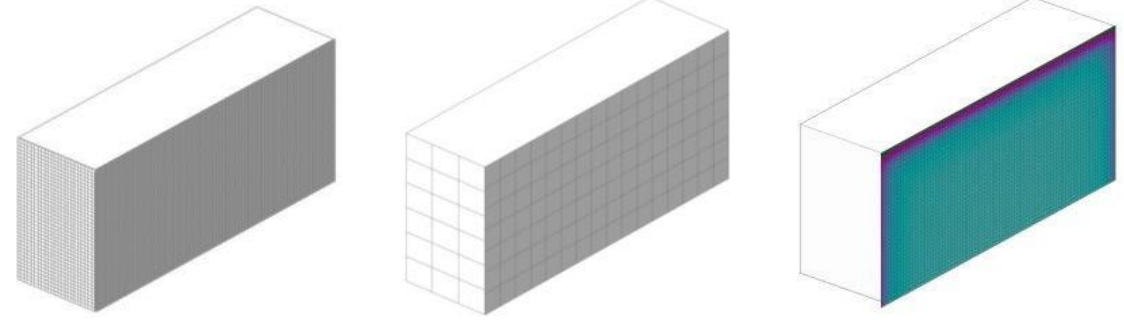

The quantity and cost variables pertinent to curtain wall components are taken into account with remaining inputs as material and total surface area information is essential for calculating the total cost of components. Subordinate inputs of other variables (width, length, and thickness) that go into the generative design process will instantly impact the total façade cost. The generative design method requires determining the delimiters and their value ranges (minimum and maximum) to set up a model. Later, this file which consists of six dependent parts was transferred to Project Refinery to obtain twenty design solutions with optimized option (Figure 10).

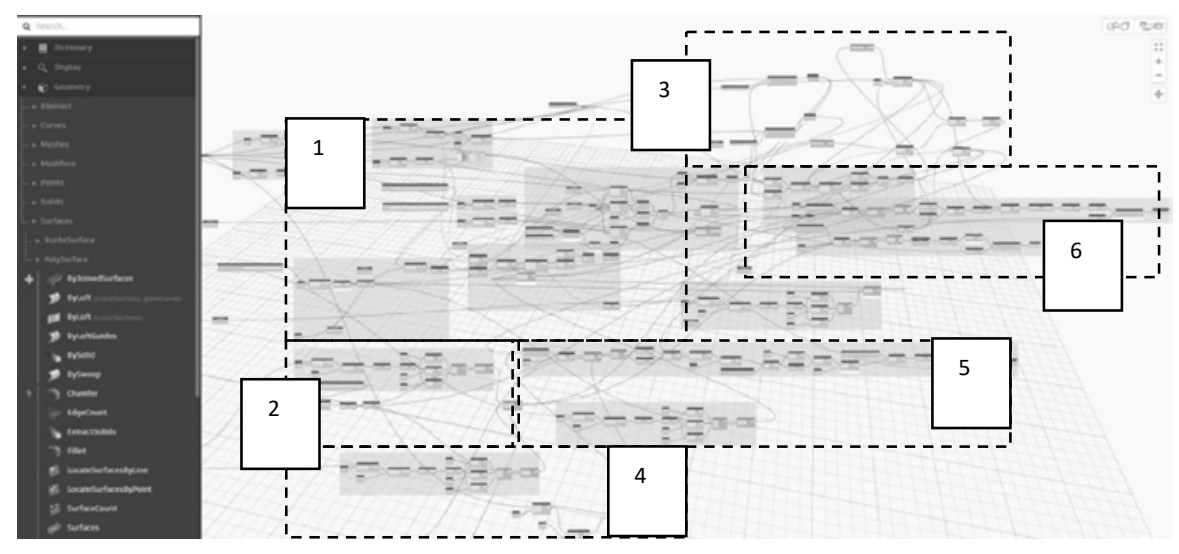

\section{RESULTS}

A linear workflow, which starts with scrutinizing in-depth literature and continues with the creation of geometric definitions, the identification of the variables, and the preparation of datasets for the variables, was adopted to create a keen virtual environment for the generative design approach. After determining the case study parameters, initial settings were tested immediately on a trial-and-error basis. All input values were strictly bound to the case study surface area. The boundaries of trials were determined by the manual relay of shading lines on the
Figure 9. Identical façade elements and their intersection points on building skin surface

Figure 10. Backend development phases 
Figure 11. Output of parallel coordinates plot for the case study and initial design solutions
A Case Study on Generative Building Skin Forming by Employing Building Information Modelling (BIM) Tools

façade. Twenty design solutions and six seed values were used with the optimized method in the automatic calculations. The parallel plot enumerates 12 parameters (length, height, thickness, unit area, void ratio, surface area, frequency, the building unit cost, slab thickness, storey height, assembly(labor) cost, and material cost) whose relationships are examined from left to right on a parallel coordinates (Figure 11). The three categories of materials (transparent, solid, and partial solid/transparent) were used separately in the optimization and the findings were monitored to create preliminary cost estimates. Among the three cost parameters in the list, building unit cost is the amalgamation of assembly (labor) costs and material costs.

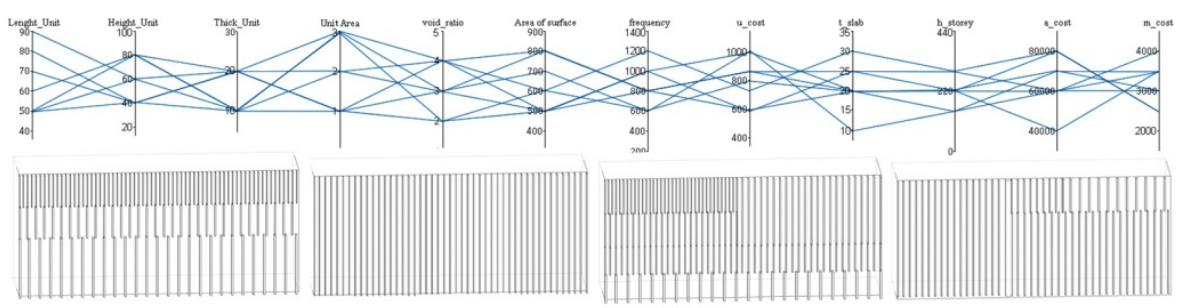

Considering the results, the floor height and slab thickness parameters are equally effective as frequency and material type parameters on the cost in the general equation. Besides, the type of material was shown to affect the unit price and its subcategories dramatically. It was also shown that the void area ratio had an inverse relationship to the surface area, building unit cost, assembly/labor unit cost, and material unit cost.

\section{CONCLUSION}

The use of the generative design in architecture provides numerous opportunities for the designer in the decision-making process. However, understanding design inputs and establishing meaningful relationships between them requires a series of steps, e.g., gathering, selecting, filtering, and managing raw data. Each step helps to sort out possible problems. In principle, algorithms are essential for supporting relationships between various design inputs during the pre-design phase. Architects/designers can choose one of the design variations and continue to improve it or test against their preliminary ideas. The tools that fall in-between building information modeling (BIM) and generative design (GD) systems enable designers to enjoy the multiple solution environment. With the increasing possibilities of design, it is obvious that many opportunities come forth. However, this requires careful organization and management of architectural and spatial geometries. Besides, form creation operations require a great deal of proficiency in both architectural design processes and programming knowledge. Unfortunately, not every novice designer is expected to be competent in programming so specialized applications and auxiliary instruments fill this gap. In this study, varying curtain wall types such as 
glass, solid cladding, and hybrid were explored in schematic detail. Curtain wall construction techniques and materials are progressively improving and getting more attention as demand for high-rise buildings soars. Inherently, this raises concerns about the protection, design, and repair of façades. In this study, it was also attempted to create curtain wall geometries using generative design methods. One of the challenges encountered throughout the entire process was the collection of information needed to calculate the approximate cost. Since the approximate cost is calculated based on the preliminary design stages, it took time to identify the cost values. Therefore, the type and number of the material studied remained limited. In the scope of the this study, BIM and generative systems have been tested which will benefit more designers in the near future. One aspect that is considered advantageous during the study is the coordination caused by the fact that file transfers are in the BIM environment. Generative design models contribute to the implicit knowledge of the designer by characterizing the problem through multiple options for each condition. While in its infancy today, generative design models are likely to become one of the domains frequently used in the design works of the near future. Finally, future studies with comprehensive data sets are recommended to achieve the desired quality and quantity levels.

\section{ACKNOWLEDGEMENT}

I would like to thank Mr. Erhan Ertem (MSc. Architect) for his critical perspective and valuable comments.

\section{CONFLICT OF INTEREST}

No conflict of interest was declared by the author.

\section{FINANCIAL DISCLOSURE}

The author declared that this study has received no financial support.

\section{ETHICS COMMITTEE APPROVAL}

Ethics committee approval was not required for this article.

\section{REFERENCES}

Abrishami, S., Goulding, J., Rahimian, F. P., \& Ganah, A. (2014). Integration of BIM and generative design to exploit AEC conceptual design innovation. Information Technology in Construction, 19, 350-359.

Aish, R. (2003). Bentley's Generative Components: a Design Tool for Exploratory Architecture. Bentley Systems Inc.

Autodesk Flow Design Software. (2017, June). Flow Design Overview. https://www.autodesk.com/products/flow-design/overview

Autodesk Revit 2020 Software. (2019, August). General View. https://www.autodesk.com.tr/products/revit/subscribe 
A Case Study on Generative Building Skin Forming by Employing Building Information Modelling (BIM) Tools

Autodesk Blog. (2020, April 8). Generative Design in Revit now available. Revit Official Blog.

https://blogs.autodesk.com/revit//2020/04/08/generative-design-inrevit/

Barazzetti, L., Banfi, F., Brumana, R., Gusmeroli, G., Previtali, M., \& Schiantarelli, G. (2015). Cloud-to-BIM-to-FEM: Structural simulation with accurate historic BIM from laser scans. Simulation Modelling Practice and Theory, 57, 71-87. https://doi.org/10.1016/j.simpat .2015.06.004

Bentley, P. (1999). An introduction to evolutionary design by computers. Evolutionary design by computers, 1-73. Morgan Kaufmann Publishers.

Bryde, D., Broquetas, M., \& Volm, J. M. (2013). The project benefits of Building Information Modelling (BIM). International Journal of Project Management,31(7),971-980. https://doi.org/10.1016/ j.ijproman.20 12.12.001

Chase, S. C. (2005). Generative design tools for novice designers: Issues for selection. Automation in Construction, 14(6), 689-698. https://doi.org/10.1016/j.autcon.2004.12.004

Dore, C., Murphy, M., McCarthy, S., Brechin, F., Casidy, C., \& Dirix, E. (2015). Structural simulations and conservation analysis -historic building information model (HBIM). ISPRS - International Archives of the Photogrammetry, Remote Sensing and Spatial Information Sciences, $X L$ 5/W4, 351-357. https://doi.org/10.5194/isprsarchives-xl-5-w4-3512015

Dynamo. (2020, April). Open source graphical programming for design. https://dynamobim.org/

Eastman, C. M., Eastman, C., Teicholz, P. M., Sacks, R., \& Liston, K. (2011). BIM handbook: A guide to building information modeling for owners, managers, designers, engineers and contractors. John Wiley \& Sons.

Fai, S., \& Rafeiro, J. (2014). Establishing an appropriate level of detail (LoD) for a building information model (BIM)-West Block, Parliament

Elbiz, G. \& Yönder, V. M. (2020). The Daylight Quality in Educational Buildings in Terms of The Form of Skylight, International Symposium of Architecture, Technology and Innovation (ATI), 26 - 33.

Gross, B., Bohnacker, H., Laub, J., \& Lazzeroni, C. (2012). Generative design: Visualize, program, and create with JavaScript in p5.js. Princeton Architectural Press.

Ferreira, B., \& Leitão, A. (2015). Generative Design for Building Information Modeling. CumInCAD. http://papers.cumincad.org/data/ works/att/ecaade2015_118.content.pdf

Frazer, J. (2002). Creative Design and the Generative Evolutionary Paradigm. Creative Evolutionary Systems, 253-274. Elsevier. https://doi.org/10.1016/b978-155860673-9/50047-1

Gagne, J., \& Andersen, M. (2012). A generative facade design method based on daylighting performance goals. Journal of Building Performance Simulation, 5(3), 141-154. https://doi.org/10.1080/19401493.2010.5 49572. 
Garber, R. (2014). BIM design: realising the creative potential of building information modelling. John Wiley \& Sons.

Grasshopper 3D. (2019, August). About Grasshopper. https://www.grasshopper3d.com/

Kang, T. W., \& Hong, C. H. (2015). A study on software architecture for effective BIM/GIS-based facility management data integration. Automation in Construction, 54, 25-38. https://doi.org/10.1016/ j.autcon.2015.03.019

Krish, S. (2011). A practical generative design method. Computer-Aided Design, 43(1), 88-100. https://doi.org/10.1016/j.cad.2010.09.009.

Krygiel, E., \& Nies, B. (2008). Green BIM: Successful sustainable design with building information modeling. John Wiley \& Sons.

Latiffi, A. A., Mohd, S., Kasim, N., \& Fathi, M. S. (2013). Building information modeling (BIM) application in Malaysian construction industry. International Journal of Construction Engineering and Management, 2(4A), 1-6.

McCormack, J., Dorin, A., \& Innocent, T. (2004). Generative Design: a paradigm for design research. Proceedings of Futureground, Design Research Society, Melbourne.

McKnight, M. (2017). Generative design: What it is? How is it being used? Why it's a game changer. KnE Engineering, 2(2), 176. https://doi.org/10.18502/keg.v2i2.612

MGM. (2019, November). Turkish State Meteorological Service. www.mgm.gov.tr /veridegerlendirme /il-ve-ilceler-istatistik.aspx?m=IZMIR

Migilinskas, D., Popov, V., Juocevicius, V., \& Ustinovichius, L. (2013). The

Benefits, Obstacles and Problems of Practical Bim Implementation. Procedia Engineering, 57, 767-774. https://doi.org/10.1016/j.proeng.20 13.04.097

Mirtschin, J. (2011). Engaging Generative BIM Workflows (pp. 1-8). http://ssi.wdfiles.com/local--files/about- us/Engaging\%20Generative \%20BIM\%20Workflows\%20submit.pdf.

Murphy, M., McGovern, E., \& Pavia, S. (2009). Historic building information modelling (HBIM). Structural Survey, 27(4), 311327. https://doi.org/10.1108/02630800910985108

Negendahl, K. (2015). Building performance simulation in the early design stage: An introduction to integrated dynamic models. Automation in Construction, 54, 39-53. https://doi.org/10.1016/j.autcon.2015.0 3.002

Project Refinery Beta. (2020, April). Information About Project Refineryhttps://www.autodesk.com/campaigns/refinery-beta

Renner, G., \& Ekárt, A. (2003). Genetic algorithms in computer aided design. Computer-Aided Design, 35(8), 709-726. https://doi.org/10 .1016/s0010-4485(03)00003-4.

Sebastian, R. (2011). Changing roles of the clients, architects and contractors through BIM.Engineering, Construction and Architectural 
A Case Study on Generative Building Skin Forming by Employing Building Information Modelling (BIM) Tools

Management, 18(2), 176-187. https://doi.org/10.1108/0969998111 1111148

Shadow Analysis 2 Software. (2019, September). Info About Software. https://deltacodes.eu/en/ShadowAnalysis2

Shea, K., Aish, R., \& Gourtovaia, M. (2005). Towards integrated performance-driven generative design tools. Automation in Construction, 14(2), 253-264. https://doi.org/10.1016/j.autcon.2004.07.002

Singh, V., \& Gu, N. (2012). Towards an integrated generative design framework. Design Studies, 33(2), 185-207. Elsevier. https://doi.org/10.1016/j.destud.2011.06.001.

SketchUp Trimble Software. (2019, November). General Info About Products. https://www.sketchup.com/

Tayfur, G. (2014). Soft computing in water resources engineering: Artificial neural networks, fuzzy logic and genetic algorithms. WIT Press.

Villaggi, L., \& Nagy, D. (2019). Generative Design for Architectural Space Planning: The Case of the Autodesk University 2017 Layout.

Yamamura, S., Fan, L., \& Suzuki, Y. (2017). Assessment of urban energy performance through integration of BIM and GIS for smart city planning. Procedia Engineering, 180, 1462-1472.

Wang, P., Wu, P., Wang, J., Chi, H. L., \& Wang, X. (2018). A critical review of the use of virtual reality in construction engineering education and training. International journal of environmental research and public health, 15(6), 1204.

Wong, K., \& Fan, Q. (2013). Building information modelling (BIM) for sustainable building design. Facilities, 31(3/4), 138-157. https://doi.org/10.1108/02632771311299412

\section{Resume}

Veli Mustafa Yönder continues his studies on computational design methodologies in architecture and earned a bachelor's degree in architecture from Izmir Institute of Technology, Turkey. He completed his master's degree in architecture at the same university in 2019. He is currently a Ph.D. candidate in the Department of Architecture at Izmir Institute of Technology. After completing his bachelor's degree, he focused on gaining professional experience in an Architectural firm until he began his academic career as a research assistant. 